\title{
Ruthenium-Catalyzed Dehydrogenative Decarbonylation of Primary Alcohols
}

\author{
Mazziotta, Andrea; Madsen, Robert
}

Published in:

European Journal of Organic Chemistry

Link to article, DOI:

10.1002/ejoc.201701173

Publication date:

2017

Document Version

Peer reviewed version

Link back to DTU Orbit

Citation (APA):

Mazziotta, A., \& Madsen, R. (2017). Ruthenium-Catalyzed Dehydrogenative Decarbonylation of Primary

Alcohols. European Journal of Organic Chemistry, 2017(36), 5417-5420. https://doi.org/10.1002/ejoc.201701173

\section{General rights}

Copyright and moral rights for the publications made accessible in the public portal are retained by the authors and/or other copyright owners and it is a condition of accessing publications that users recognise and abide by the legal requirements associated with these rights.

- Users may download and print one copy of any publication from the public portal for the purpose of private study or research.

- You may not further distribute the material or use it for any profit-making activity or commercial gain

- You may freely distribute the URL identifying the publication in the public portal

If you believe that this document breaches copyright please contact us providing details, and we will remove access to the work immediately and investigate your claim. 


\title{
Ruthenium-Catalyzed Dehydrogenative Decarbonylation of Primary Alcohols
}

\author{
Andrea Mazziotta and Robert Madsen*[a]
}

\begin{abstract}
Dehydrogenative decarbonylation of a primary alcohol involves the release of both dihydrogen and carbon monoxide to afford the one-carbon shorter product. The transformation has now been achieved with a ruthenium-catalyzed protocol by using the complex $\mathrm{Ru}(\mathrm{COD}) \mathrm{Cl}_{2}$ and the hindered monodentate ligand $\mathrm{P}(\mathrm{O}-$ tolyl $)_{3}$ in refluxing $p$-cymene. The reaction can be applied to both benzylic and long chain linear aliphatic alcohols. The intermediate aldehyde can be observed during the transformation, which is therefore believed to proceed through two separate catalytic cycles involving first dehydrogenation of the alcohol and then decarbonylation of the resulting aldehyde.
\end{abstract}

The dehydrogenation of an alcohol and the decarbonylation of an aldehyde constitute fundamental catalytic reactions in organic synthesis. The dehydrogenation of an alcohol with the release of dihydrogen and the subsequent transformation of the carbonyl compound has received much attention for more than a decade where the most prominent catalysts have been a series of ruthenium and iridium complexes. ${ }^{[1]}$ The decarbonylation of aldehydes with the liberation of carbon monoxide has also been investigated significantly in the same period especially with rhodium complexes. ${ }^{[2]}$

In 2012 two groups simultaneously presented a combination of the two reactions, i.e. a dehydrogenative decarbonylation, where a single metal complex catalyzes both the dehydrogenation of a primary alcohol and the subsequent decarbonylation of the resulting aldehyde. ${ }^{[3,4]}$ This is a more challenging transformation since the catalyst should be able to release both dihydrogen and carbon monoxide, which are known ligands for a variety of metals. Our group disclosed the iridium catalyst $\left[\operatorname{Ir}(\mathrm{COD}) \mathrm{Cl}_{2}\right.$ in the presence of $\mathrm{BINAP}^{[3]}$ while the Sadow group published the rhodium catalyst $\left[\mathrm{To}^{\mathrm{M}} \mathrm{Rh}(\mathrm{CO})_{2}\right]$ under photolytic conditions. ${ }^{[4]}$ The iridium-catalyzed reaction was carried out with a $5 \%$ catalyst loading in mesitylene at $164{ }^{\circ} \mathrm{C}^{[3]}$ while the rhodium-catalyzed procedure used a $10 \%$ loading in benzene at room temperature with a $450 \mathrm{~W}$ medium pressure Hg lamp. ${ }^{[4]}$ Recently, we presented a thorough mechanistic study of the iridium-catalyzed dehydrogenative decarbonylation where the reaction was shown to go through two catalytic cycles (dehydrogenation and decarbonylation) with the square planar complex $\operatorname{IrCl}(\mathrm{CO}) \mathrm{BINAP}$ as the catalytically active species in both cycles. ${ }^{[5]}$ The $[\operatorname{Ir}(\mathrm{COD}) \mathrm{Cl}]_{2} / \mathrm{BINAP}$ system was also used for releasing dihydrogen and carbon monoxide, i.e. syngas, from

[a] A. Mazziotta, Prof. Dr. R. Madsen Department of Chemistry Technical University of Denmark 2800 Kgs. Lyngby (Denmark)

E-mail: rm@kemi.dtu.dk

http://www.kemi.dtu.dk

Supporting information for this article is given via a link at the end of the document. diols and polyols in a two-chamber system where the liberated syngas was utilized for hydroformylation of olefins or reductive carbonylation of aryl halides in the second chamber. ${ }^{[6]}$

In a recent report, palladium-on-carbon was used for fragmentation of lignin samples at $200{ }^{\circ} \mathrm{C}$ and the dehydrogenative decarbonylation of a primary alcohol was observed in the degradation of one model compound. ${ }^{[7]}$ In another recent study, palladium-on-carbon and rhodium-oncarbon were shown to perform the dehydrogenation of primary alcohols into carboxylic acids where the dehydrogenative decarbonylation of the alcohol was observed as a side reaction. ${ }^{[8]}$ Palladium acetate has also been used for removing a hydroxymethyl group from primary alcohols although the reaction was performed under an atmosphere of dioxygen in a closed vial and therefore does not proceed through the liberation of syngas. ${ }^{[9]}$

As a result, the iridium system $[\operatorname{Ir}(\mathrm{COD}) \mathrm{Cl}]_{2} / \mathrm{BINAP}$ and the rhodium complex $\left[\mathrm{To}^{\mathrm{M}} \mathrm{Rh}(\mathrm{CO})_{2}\right]$ are so far the only catalysts that have been shown to perform the dehydrogenative decarbonylation on a variety of primary alcohols and where the liberated syngas has been identified. However, iridium and rhodium are also some of the most expensive transition metals and it would be attractive to develop cheaper catalysts for this transformation. As noted above, a key requirement is that the metal complex is able to perform both the dehydrogenation and the decarbonylation where dihydrogen as well as carbon monoxide are released from the metal.

Ruthenium complexes have been widely employed for the dehydrogenation of alcohols, ${ }^{[1]}$ but a few reports have also shown that similar ruthenium complexes can be used to catalyze the decarbonylation of aldehydes. ${ }^{[10]}$ Consequently, it should be possible to identify a ruthenium complex that will mediate both the dehydrogenation and the decarbonylation at the same time, and without using any stoichiometric additives. Herein, we describe our development of the ruthenium-catalyzed dehydrogenative decarbonylation of primary alcohols by using $\mathrm{Ru}(\mathrm{COD}) \mathrm{Cl}_{2}$ in the presence of $\mathrm{P}(0 \text {-tolyl })_{3}$.

2-Naphthylmethanol was selected as the test substrate for the exploratory studies since the intermediate aldehyde and the product naphthalene are both easily detected by GC regardless of the employed solvent. The previously described rutheniumcatalyzed dehydrogenations and decarbonylations have all been performed with different ruthenium(0) and ruthenium(II) complexes. ${ }^{[1,10]}$ Therefore, 2-naphthylmethanol was first reacted with several of these complexes to identify the optimum catalyst precursor (Table 1). The reactions were carried out under a flow of nitrogen in a Schlenk tube and stopped after $16 \mathrm{~h}$ at which time full conversion of the starting alcohol had not been achieved. The reaction with $\mathrm{Ru}_{3}(\mathrm{CO})_{12}$ gave $10 \%$ yield of naphthalene in refluxing xylene (entry 1 ) while the yield increased to $26 \%$ in refluxing $p$-cymene ${ }^{[11]}$ (entry 2 ). A further improvement to $39 \%$ was obtained in the presence of $\mathrm{PPh}_{3}$ (entry 3 ) and a significant amount of 2-naphthaldehyde could 
also be observed in all three cases. Various ruthenium(II) complexes were then tested where $\mathrm{Ru}(\mathrm{CO}) \mathrm{ClH}\left(\mathrm{PPh}_{3}\right)_{3}$ gave a poor conversion (entry 4). Better results were obtained with $\mathrm{RuCl}_{2}\left(\mathrm{PPh}_{3}\right)_{3}$ although the decarbonylation step appeared to be slow (entries 5 and 6). Again, a higher conversion and yield were achieved in p-cymene (b.p. $177^{\circ} \mathrm{C}$ ) than in xylene (b.p. $138^{\circ} \mathrm{C}$ ) and the former was therefore selected as the solvent for the further optimization. DMSO and tert-butanol were also investigated as solvents, but no formation of naphthalene was observed in these two cases (results not shown). A phosphine ligand is crucial for the overall dehydrogenative decarbonylation as illustrated with $\left[\mathrm{Ru}\left(p \text {-cymene) } \mathrm{Cl}_{2}\right]_{2}\right.$ and $\mathrm{Ru}(\mathrm{COD}) \mathrm{Cl}_{2}$ (can also be written as $\left.\left[\mathrm{Ru}(\mathrm{COD}) \mathrm{Cl}_{2}\right]_{\mathrm{n}}\right)$. None of the desired product was detected in the absence of a phosphine (entries 7 and 8), but in the presence of $\mathrm{PPh}_{3}$, naphthalene was formed in $14 \%$ and $38 \%$ yield, respectively (entries 9 and 10). In all, the best results were obtained with $\mathrm{Ru}_{3}(\mathrm{CO})_{12}$ and $\mathrm{Ru}(\mathrm{COD}) \mathrm{Cl}_{2}$ in the presence of $\mathrm{PPh}_{3}$ and these two complexes were therefore selected for the further optimization with different phosphine ligands.

Table 1. Dedydrogenative decarbonylation with different ruthenium catalysts. ${ }^{[\mathrm{a}]}$

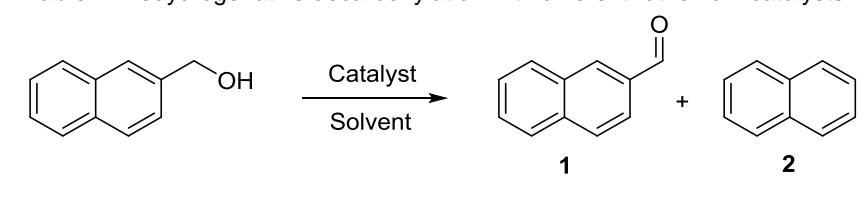

\begin{tabular}{|c|c|c|c|c|}
\hline Entry & Catalyst & Solvent & $\begin{array}{l}\text { Yield of } \\
1[\%]^{[b]}\end{array}$ & $\begin{array}{l}\text { Yield of } \\
2[\%]^{[b]}\end{array}$ \\
\hline 1 & $1.7 \% \mathrm{Ru}_{3}(\mathrm{CO})_{12}$ & xylene & 23 & 10 \\
\hline 2 & $1.7 \% \mathrm{Ru}_{3}(\mathrm{CO})_{12}$ & p-cymene & 25 & 26 \\
\hline 3 & $1.7 \% \mathrm{Ru}_{3}(\mathrm{CO})_{12}+10 \% \mathrm{PPh}_{3}$ & p-cymene & 50 & 39 \\
\hline 4 & $5 \% \mathrm{Ru}(\mathrm{CO}) \mathrm{ClH}\left(\mathrm{PPh}_{3}\right)_{3}$ & xylene & 3 & 5 \\
\hline 5 & $5 \% \mathrm{RuCl}_{2}\left(\mathrm{PPh}_{3}\right)_{3}$ & xylene & 55 & 9 \\
\hline 6 & $5 \% \mathrm{RuCl}_{2}\left(\mathrm{PPh}_{3}\right)_{3}$ & p-cymene & 43 & 20 \\
\hline 7 & $2.5 \%\left[\mathrm{Ru}(p \text {-cymene }) \mathrm{Cl}_{2}\right]_{2}$ & p-cymene & 9 & 0 \\
\hline 8 & $5 \% \mathrm{Ru}(\mathrm{COD}) \mathrm{Cl}_{2}$ & p-cymene & 14 & 0 \\
\hline 9 & $\begin{array}{l}2.5 \% \quad\left[\mathrm{Ru}(p \text {-cymene }) \mathrm{Cl}_{2}\right]_{2}+ \\
10 \% \mathrm{PPh}_{3}\end{array}$ & p-cymene & 51 & 14 \\
\hline 10 & $5 \% \mathrm{Ru}(\mathrm{COD}) \mathrm{Cl}_{2}+10 \% \mathrm{PPh}_{3}$ & $p$-cymene & 27 & 38 \\
\hline
\end{tabular}

[a] Reaction conditions: 2-Naphthylmethanol (1.0 mmol), catalyst, solvent (2 $\mathrm{mL}$ ), reflux, $16 \mathrm{~h}$. [b] GC yield.

First, several electron-rich phosphines were investigated where $\mathrm{PCy}_{3}$ gave complete conversion of the alcohol and almost $50 \%$ yield of naphthalene for both ruthenium complexes (Table 2, entry 1). 2-Naphthaldehyde accounted for the remaining portion, which again points to the decarbonylation as the slow step. Significantly lower yields were observed with $\mathrm{PBu}_{3}, \mathrm{P}(t \mathrm{Bu})_{3}$ and $\mathrm{P}(2 \text {-furyl })_{3}$ due to incomplete conversion of the alcohol and accumulation of the aldehyde in the mixture (entries $2-4$ ). Insufficient conversion of the alcohol and the aldehyde were also observed with several bidentate phosphine ligands leading to a moderate or poor yield of naphthalene (entries 5 - 10). Therefore, attention was diverted back to the monodentate triphenylphosphine-type ligands. No improvement was observed with an electron-donating or an electron-withdrawing substituent in the para position (entries 11 and 12). However, using the more hindered ligand $\mathrm{P}(\mathrm{o} \text {-tolyl })_{3}$ increased the yield of naphthalene to $85 \%$ for $\mathrm{Ru}(\mathrm{COD}) \mathrm{Cl}_{2}$ with none of the aldehyde remaining (entry 13). The amount of the phosphine was evaluated and a lower loading dramatically decreased the yield of the product due to incomplete conversion of the alcohol and the intermediate aldehyde (entries 14 and 15). However, increasing the amount of the ligand slightly improved the yield of naphthalene with $15 \%$ as the best result (entries $16-18$ ). 2 Naphthaldehyde was not observed in these entries and the reaction in entry 17 was already completed after $8 \mathrm{~h}$. Therefore, $5 \%$ of $\mathrm{Ru}(\mathrm{COD}) \mathrm{Cl}_{2}$ and $15 \%$ of $\mathrm{P}(o \text {-tolyl })_{3}$ in refluxing $p$-cymene were selected as the optimum conditions for the dehydrogenative decarbonylation.

Table 2. Phosphine ligands for the ruthenium-catalyzed dehydrogenative decarbonylation. ${ }^{[a]}$
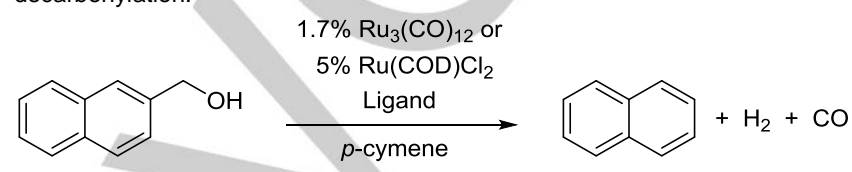

\begin{tabular}{|c|c|c|c|}
\hline Entry & Ligand & $\begin{array}{l}\text { Yield with } \\
\mathrm{Ru}_{3}(\mathrm{CO})_{12}[\%]^{[\mathrm{b}]}\end{array}$ & $\begin{array}{l}\text { Yield with } \\
\mathrm{Ru}(\mathrm{COD}) \mathrm{Cl}_{2}[\%]^{[\mathrm{b}]}\end{array}$ \\
\hline 1 & $10 \%$ РСуз & 49 & 48 \\
\hline 2 & $10 \% \mathrm{PBu}_{3}$ & 4 & 4 \\
\hline 3 & $10 \% \mathrm{P}(t \mathrm{Bu})_{3}$ & 23 & 6 \\
\hline 4 & $10 \% \mathrm{P}(2 \text {-furyl })_{3}$ & 5 & 4 \\
\hline 5 & $5 \%$ dppe & 28 & 18 \\
\hline 6 & $5 \%$ dppp & 15 & 34 \\
\hline 7 & $5 \% \mathrm{dppf}$ & 41 & 23 \\
\hline 8 & $5 \%$ BIPHEP & 37 & 15 \\
\hline 9 & $5 \%$ DPEPhos & 13 & 5 \\
\hline 10 & $5 \%$ Xantphos & 0 & 4 \\
\hline 11 & $10 \% \mathrm{P}\left(p-\mathrm{MeOC}_{6} \mathrm{H}_{4}\right)_{3}$ & 32 & 22 \\
\hline 12 & $10 \% \mathrm{P}\left(p-\mathrm{FC}_{6} \mathrm{H}_{4}\right)_{3}$ & 11 & 21 \\
\hline 13 & $10 \% \mathrm{P}(\text { o-tolyl })_{3}$ & 28 & 85 \\
\hline 14 & $5 \% \mathrm{P}(0 \text {-tolyl })_{3}$ & - & 31 \\
\hline 15 & $2.5 \% \mathrm{P}(o \text {-tolyl })_{3}$ & - & 16 \\
\hline 16 & $12.5 \% \mathrm{P}(o \text {-tolyl })_{3}$ & - & 91 \\
\hline 17 & $15 \% \mathrm{P}(\text { o-tolyl })_{3}$ & - & $92^{[\mathrm{c}]}$ \\
\hline 18 & $20 \% \mathrm{P}(0 \text {-tolyl })_{3}$ & - & 90 \\
\hline
\end{tabular}

[a] Reaction conditions: 2-Naphthylmethanol $(1.0 \mathrm{mmol})$, catalyst, ligand, $p$ cymene $(2 \mathrm{~mL}), 177^{\circ} \mathrm{C}, 16 \mathrm{~h}$. [b] GC yield. [c] Reaction time $8 \mathrm{~h}$.

This protocol was then subjected to a variety of primary alcohols to explore the substrate scope and limitations of the transformation (Table 3). 1-Naphthylmethanol underwent the reaction smoothly and afforded naphthalene in 95\% yield after 8 h (entry 1). The dehydrogenative decarbonylation could also be applied to several para-substituted benzyl alcohols although the 
WILEY-VCH

yield was dependent on the nature of the substituent. The tertbutyl- and the phenyl-substituted substrate afforded the products in $88 \%$ and $83 \%$ yield, respectively, while p-methoxybenzyl alcohol gave $75 \%$ yield (entries 2 - 4). p-Benzyloxybenzyl alcohol furnished $72 \%$ yield and 3,5-di(benzyloxy)benzyl alcohol $63 \%$ yield, and both products could be isolated from the highboiling solvent (entries 5 and 6 ). The corresponding phenols and toluene were not observed by GC and therefore hydrogenolysis of the benzyl ethers does not appear to be a side reaction. $p$ Bromobenzyl alcohol gave bromobenzene in $53 \%$ yield (entry 7 ) and benzene was not detected by GC. This, however, does not exclude a competing dehalogenation since benzene is highly volatile under the reaction conditions as noted below. $p$ Methylthiobenzyl alcohol, on the other hand, only furnished $13 \%$ yield of thioanisole (entry 8 ) which is most likely due to inhibition of the ruthenium catalyst by the thio ether since the starting material and the intermediate aldehyde were also observed in a $1: 1$ ratio after the reaction.

The dehydrogenative decarbonylation could also be applied to long chain aliphatic primary alcohols although these substrates reacted more slowly and a longer reaction time was usually necessary. Decan-1-ol and eicosan-1-ol were converted into the one-carbon shorter alkane in $75 \%$ and $82 \%$ yield, respectively, while 10-phenyldecan-1-ol afforded nonylbenzene in $63 \%$ yield (entries $9-11$ ). Smaller alcohols, on the contrary, gave low yields, which is presumably due to the significantly lower boiling point of the products as compared to p-cymene resulting in co-evaporation with the liberated syngas during the reaction. As an example, benzyl alcohol underwent complete conversion in less than $5 \mathrm{~h}$, but benzene or other products could not be detected by GC after the reaction. In the same way, $p$ methylbenzyl alcohol was converted completely after $3 \mathrm{~h}$, but the only product observed was toluene and only in $38 \%$ yield (results not shown). Some co-evaporation of the product from the dehydrogenative decarbonylation was also envisioned in the earlier study with palladium and rhodium catalysts. ${ }^{[8]}$

Table 3. Ruthenium-catalyzed dehydrogenative decarbonylation of various primary alcohols. ${ }^{[a]}$

Entry Substrate

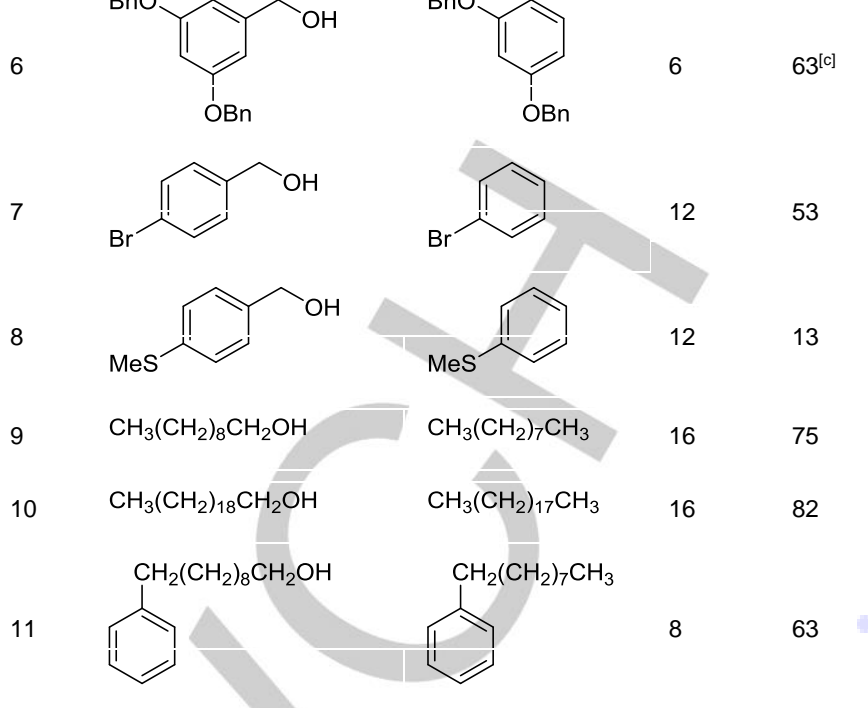

[a] Reaction conditions: Alcohol $(1.0 \mathrm{mmol}), \mathrm{Ru}(\mathrm{COD}) \mathrm{Cl}_{2}(0.05 \mathrm{mmol}), \mathrm{P}(o$ tolyl $)_{3}(0.15 \mathrm{mmol}), p$-cymene $(2 \mathrm{~mL}), 177^{\circ} \mathrm{C}, t$. [b] GC yield. [c] Isolated yield.

The gas evolution was measured by connecting the Schlenk tube from the reaction with $1.0 \mathrm{mmol}$ of 2-naphthylmethanol to a burette filled with water. ${ }^{[3]}$ The transformation gave $92 \%$ yield of naphthalene (Table 2, entry 17) and a total of $1.6 \mathrm{mmol}$ of gas was collected confirming the release of two gaseous molecules during the dehydrogenative decarbonylation. The identity of the liberated gas was established by trapping dihydrogen and carbon monoxide in a two-chamber system as described previously. ${ }^{[3]}$ The reaction order in ruthenium was determined by measuring initial rates at different catalyst loadings while keeping the concentration of the substrate constant. This gave a slope of 1.07 , which shows a first order reaction in ruthenium. The intermediate aldehyde was detected when monitoring the transformation under the optimized conditions by GC (Figure 1). Actually, in the beginning of the reaction, up to $20 \%$ of the aldehyde accumulated in the mixture.

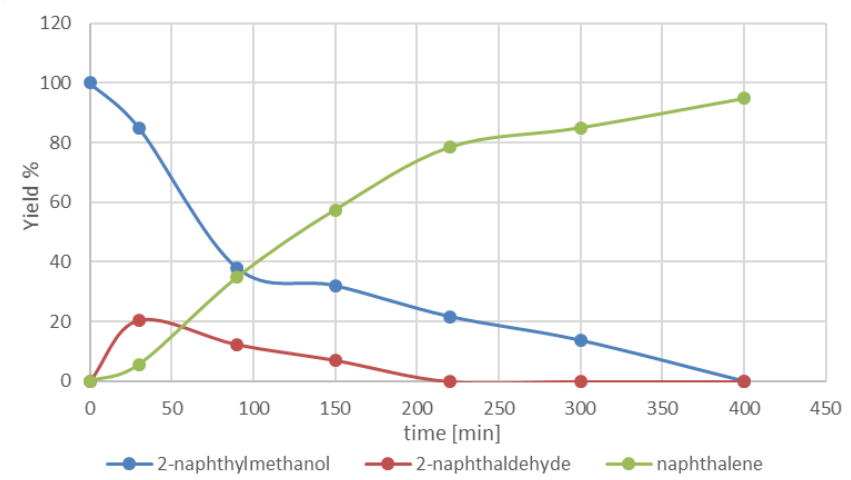

Figure 1. 2-Naphthaldehyde formation during the reaction.

The kinetic isotope effect (KIE) was determined for the overall dehydrogenative decarbonylation as well as for the decarbonylation step alone. By measuring initial rates for both the conversion of 2-naphthylmethanol and for the reaction of 2$\alpha, \alpha-\left[D_{2}\right]$-naphthylmethanol, a KIE of 2.15 was found. Some hydrogen - deuterium scrambling, however, was observed in the experiment with 2- $\alpha, \alpha-\left[D_{2}\right]$-naphthylmethanol indicating that the dehydrogenation is a reversible reaction. The same scrambling has also been observed in other dehydrogenations with 
ruthenium catalysts showing the presence of a ruthenium dihydride species in the catalytic cycle. ${ }^{[12]}$ As a result, the measured KIE value of 2.15 is too small, but it does show that cleavage of the $\mathrm{C}-\mathrm{H}$ bond is a slow step in the overall transformation. The KIE for the decarbonylation step was measured with 2-naphthaldehyde and 2- $\alpha$-[D]-naphthaldehyde and found to be 1.16. ${ }^{[13]}$ This rather modest value suggests that $\mathrm{C}-\mathrm{H}$ cleavage in the aldehyde (e.g. by oxidative addition to ruthenium) is not the rate-determining step and the KIE for the overall transformation therefore relates to the alcohol dehydrogenation. Although, these kinetic experiments do not lead to a detailed mechanism, the most likely scenario is a ruthenium(II) phosphine complex as the catalytically active species responsible for both the dehydrogenation and the decarbonylation in two separate catalytic cycles as determined for the corresponding iridium-catalyzed transformation. ${ }^{[5]}$

In conclusion, we have described a ruthenium-catalyzed protocol for the dehydrogenative decarbonylation of primary alcohols where dihydrogen and carbon monoxide are released. The transformation employs $5 \%$ of $\mathrm{Ru}(\mathrm{COD}) \mathrm{Cl}_{2}$ and $15 \%$ of $\mathrm{P}(\mathrm{o}$ tolyl $)_{3}$ in refluxing $p$-cymene and can be applied to both benzylic and non-benzylic primary alcohols. The intermediate aldehyde can be observed during the reaction, which is therefore believed to proceed through two separate catalytic cycles.
[6] a) S. H. Christensen, E. P. K. Olsen, J. Rosenbaum, R. Madsen, Org. Biomol. Chem. 2015, 13, 938-945; b) J. J. Verendel, M. Nordlund, P. G. Andersson, ChemSusChem 2013, 6, 426-429.

[7] F. Gao, J. D. Webb, H. Sorek, D. E. Wemmer, J. F. Hartwig, ACS Catal. 2016, 6, 7385-7392.

[8] Y. Sawama, K. Morita, S. Asai, M. Kozawa, S. Tadokoro, J. Nakajima, Y. Monguchi, H. Sajiki, Adv. Synth. Catal. 2015, 357, 1205-1210.

[9] A. Modak, T. Naveen, D. Maiti, Chem. Commun. 2013, 49, 252-254.

[10] a) N. Sieffert, R. Réocreux, P. Lorusso, D. J. Cole-Hamilton, M. Bühl Chem. Eur. J. 2014, 20, 4141-4155; b) J. G. de Vries, G. Roelfes, R. Green, Tetrahedron Lett. 1998, 39, 8329-8332; c) T. Kondo, M. Akazome, Y. Tsuji, Y. Watanabe, J. Org. Chem. 1990, 55, 1286-1291; d) G. Domazetis, B. Tarpey, D. Dolphin, B. R. James, J. Chem. Soc. Chem. Commun. 1980, 939-940.

[11] $p$-Cymene is a biorenewable compound and was recently demonstrated as a good alternative solvent for the ruthenium-catalyzed olefin metathesis reaction, see: A. V. Granato, A. G. Santos, E. N. dos Santos, ChemSusChem 2017, 10, 1832-1837.

[12] a) A. Maggi, R. Madsen, Organometallics 2012, 31, 451-455; b) M. Takahashi, K. Oshima, S. Matsubara, Chem. Lett. 2005, 34, 192-193.

[13] The reaction time necessary for the complete decarbonylation of 2 naphthaldehyde was compatible to the reaction time for the overal dehydrogenative decarbonylation of 2-naphthylmethanol, i.e. about $7 \mathrm{~h}$.

\section{Experimental Section}

\section{General procedure}

The primary alcohol $(1.0 \mathrm{mmol}), \mathrm{Ru}(\mathrm{COD}) \mathrm{Cl}_{2}(14 \mathrm{mg}, 0.05 \mathrm{mmol}), \mathrm{P}(0-$ tolyl) $)_{3}(45 \mathrm{mg}, 0.15 \mathrm{mmol})$ and a stir bar were placed in a dry Schlenk tube equipped with a cold finger and connected to the vacuum line. The tube was evacuated and filled with nitrogen three times, followed by addition of decane $(50 \mathrm{mg}$, internal standard) and p-cymene $(2 \mathrm{~mL})$. The mixture was heated on an oil bath to reflux under a flow of nitrogen and the reaction was monitored by GCMS. The yield was determined by GCMS via the internal standard or by evaporation of the solvent and purification of the residue by flash chromatography (pentane/EtOAc, 95:5).

\section{Acknowledgements}

We thank the Villum Fonden for financial support (grant 12380).

Keywords: alcohols • decarbonylation • dehydrogenation •

ruthenium • syngas

[1] a) C. Gunanathan, D. Milstein, Science 2013, 341, 1229712; b) G. E. Dobereiner, R. H. Crabtree, Chem. Rev. 2010, 110, 681-703.

[2] a) K. Ding, S. Xu, R. Alotaibi, K. Paudel, E. W. Reinheimer, J. Weatherly, J. Org. Chem. 2017, 82, 4924-4929; b) B. Gutmann, P. Elsner, T. Glasnov, D. M. Roberge, C. O. Kappe, Angew. Chem. Int. Ed. 2014, 53, 11557-11561; c) Akanksha, D. Maiti, Green Chem. 2012, 14, 2314-2320; d) T. Iwai, T. Fujihara, Y. Tsuji, Chem. Commun. 2008, 6215-6217; e) P. Fristrup, M. Kreis, A. Palmelund, P.-O. Norrby, R. Madsen, J. Am. Chem. Soc. 2008, 130, 5206-5215; f) R. N. Monrad, R. Madsen, J. Org. Chem. 2007, 72, 9782-9785.

[3] E. P. K. Olsen, R. Madsen, Chem. Eur. J. 2012, 18, 16023-16029.

[4] H.-A. Ho, K. Manna, A. D. Sadow, Angew. Chem. Int. Ed. 2012, 51, 8607-8610.

[5] E. P. K. Olsen, T. Singh, P. Harris, P. G. Andersson, R. Madsen, J. Am. Chem. Soc. 2015, 137, 834-842. 
Entry for the Table of Contents (Please choose one layout)

Layout 1:

\section{COMMUNICATION}

Text for Table of Contents

Layout 2:

\section{COMMUNICATION}

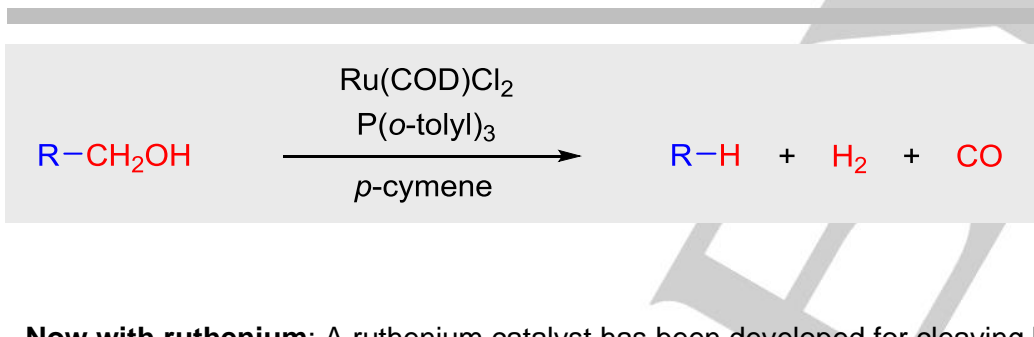

Now with ruthenium: A ruthenium catalyst has been developed for cleaving both molecular hydrogen and carbon monoxide from primary alcohols. The reaction does not require any stoichiometric additives and can be applied to number of benzylic and long chain linear aliphatic alcohols.
Author(s), Corresponding Author(s)*

\section{Page No. - Page No.}

Title

((Insert TOC Graphic here))

\section{Dehydrogenation}

A. Mazziotta, R. Madsen*

Page No. - Page No.

Ruthenium-Catalyzed

Dehydrogenative Decarbonylation of Primary Alcohols 